\title{
Large-scale synthesis of coiled-like shaped carbon nanotubes using bi-metal catalyst
}

\author{
Vemula Mohana Krishna $^{1} \cdot$ T. Somanathan ${ }^{1} \cdot$ E. Manikandan ${ }^{2,3} \cdot$ Ahmad Umar $^{4} \cdot$ M. Maaza ${ }^{2,5}$
}

Received: 13 September 2017 / Accepted: 11 November 2017 / Published online: 5 February 2018

๑) Springer-Verlag GmbH Germany, part of Springer Nature 2018

\begin{abstract}
Carbon nanomaterials (CNMs), especially carbon nanotubes (CNTs) with coiled structure exhibit scientifically fascinating. They may be projected as an innovative preference to future technological materials. Coiled carbon nanotubes (c-CNTs) on a large-scale were successfully synthesized with the help of bi-metal substituted $\alpha$-alumina nanoparticles catalyst via chemical vapor deposition (CVD) technique. Highly spring-like carbon nanostructures were observed by field emission scanning electron microscope (FESEM) examination. Furthermore, the obtained material has high purity, which correlates the X-ray photoelectron spectroscopy (XPS) and energy dispersive X-ray spectroscopy (EDX) analysis. Raman spectroscopy reveals that the carbon multi layers are well graphitized and crystalline, even if they have defects in its structure due to coiled morphology. High-resolution transmission electron microscope (HRTEM) describes internal structure and dia of the product. Ultimately, results support the activity of bi-metal impregnated $\alpha$-alumina nanoparticles catalyst to determine the high yield, graphitization and internal structure of the material. We have also studied the purified c-CNTs magnetic properties at room temperature and will be an added advantage in several applications.
\end{abstract}

Keywords Coiled-like CNTs $\cdot$ CVD technique $\cdot$ Bi-metal catalyst $\cdot$ XPS $\cdot$ SEM + EDAX $\cdot$ Magnetic properties

E. Manikandan

mani@tlabs.ac.za; maniphysics@gmail.com

T. Somanathan

soma_nano@yahoo.co.in

1 Department of Nanoscience, School of Basic Sciences, Vels University, Chennai 600117, India

2 UNESCO-UNISA Africa Chair in Nanosciences/Nanotechnology Laboratories, College of Graduate Studies, University of South Africa (UNISA), PO Box 392, Pretoria, South Africa

3 Department of Physics, Thiruvalluvar University College for Arts and Science (TUCAS), Thiruvalluvar University, Thennangur, Vellore 604408, India

4 Department of Chemistry, College of Science and Arts Promising Centre for Sensors and Electronic Devices, Najran University, PO Box1988, Najran 11001, Kingdom of Saudi Arabia

5 Materials Research Department (MRD), iThemba LABS-National Research Foundation, 1 Old Faure Road, PO Box 722, Somerset West, Western Cape 7129, South Africa

\section{Introduction}

The carbon nanomaterials (CNMs) have a broad range of applications as they are distinctive in structure along with various chemical and physical properties. Nano tubular structures of carbon such as carbon nanotubes (Iijima 1991; Segawa et al. 2016), carbon nanorings (Sai Krishna and Eswaramoorthy 2007) carbon nanocones (Ma et al. 2017) and carbon nanofibers ( $\mathrm{Li}$ et al. 2016) have been synthesized and studied. Diverse shapes of CNTs include, straight (Zhao et al. 2012), branched (Matsui et al. 2013), coiled (Choi et al. 2015), bamboo (Wang et al. 2016), fiber (Lee et al. 2016) have been accounted and possess exclusive properties for prominent applications. Among the different shapes of CNTs, coiled carbon nanotubes (c-CNTs) were proved to drag enormous attention due to outstanding properties such as high mechanical strength, electrochemical, electromagnetic wave absorption, superplasticity, elasticity, field emission and thermal properties (Cherusseri et al. 2016; Khani et al. 2016; Park et al. 2013). The extraordinary properties are being defined as fundamental components in high-strain composites, micromagnetic sensors, self-sensing mechanical resonators, high elastic

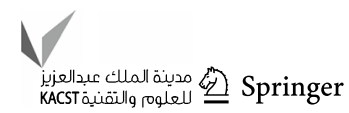


electroconductors, mechanical microsprings or actuators, wearable electronics, electromagnetic waves absorbers and electromagnetic nano transformers (Chen et al. 2003; Lau et al. 2006; Raghubanshi et al. 2016; Volodin et al. 2004).

They have unique three-dimensional (3D) coil structure, which involves twisting of tubes that appear as curved angle close to spring. CNTs with expected coiled shape can be produced through intervallic absorption of pentagon and heptagon pairs into a hexagonal carbon frame and eventually develop positively and negatively twisted faces (Amelinck et al. 1994). They also may sometimes refer to be as nanosprings, helical carbon nanotubes (h-CNTs) or carbon nanocoils (CNCs) (Zaeria and Rad 2015). Numerous works have been revealed the excellent mechanical characteristics as of their spring-like geometry and combinations of substantial properties. Usually, a spring with significant elastic strain can be stretched or compressed easily as it is valuable in mechanical devices. In addition to that of mechanical properties, they also show superior electrical features due to the existence of pentagons and heptagons within its construction (Liu et al. 2014). The extraordinary molecular and electrical qualities have been experimentally reported in the early 1990s (Motojima et al. 1993). Recently, Cherusseri et al. demonstrated that they are being used for highly flexible supercapacitors wherein a higher capacitance is observed compared to straight counterparts carried electrodes (Cherusseri et al. 2016). Furthermore, their band structures and electron density states were deliberated, thus exhibit unique feature of semi metallic characteristics, in addition to that of metallic or semi conductive electrical conduction (Akagi et al. 1995). Thus, the grand properties can be beneficial in a wide variety of applications.

The unique coiled structure is attracting much interest and various techniques have been adopted to synthesize c-CNTs include flame combustion, laser evaporation, arc discharge and chemical vapor deposition (CVD) (Kennedy et al. 2017; Mohana Krishna and Somanathan 2016; Motaung et al. 2010; Raghubanshi et al. 2016). CVD system is the most considered method amongst due to its simplicity of growth, straightforward, cost effectiveness, the applicability of a wide range of substrates, massive scalability and also comparatively low growth temperature permits carbon particle to travel gradually and form non-hexagonal carbon rings especially in c-CNTs. This technique was employed to fabricate the desired material by the pyrolysis of a hydrocarbon precursor gas on transition metal catalyst at required temperatures. $\mathrm{Ni}$ based catalysts are often used to prepare them via CVD, but they might lose their activities soon. To overcome this situation, $\mathrm{Cu}$ has been added in an appropriate amount to Ni content and conveniently to produce well-graphitized c-CNTs on a large-scale is hereby reported.

\section{Experimental procedure}

\section{Materials and methods}

The sapphire $\left(\alpha-\mathrm{Al}_{2} \mathrm{O}_{3}\right)$ nanoparticles in the range of 20-30 nm, respectively, copper nitrate $\left[\mathrm{Cu}\left(\mathrm{NO}_{3}\right)_{2} \cdot 3 \mathrm{H}_{2} \mathrm{O}\right]$ and ammonium molybdate $\left[\left(\mathrm{NH}_{4}\right)_{6} \mathrm{Mo}_{7} \mathrm{O}_{24} \cdot 4 \mathrm{H}_{2} \mathrm{O}\right]$ were purchased from SRL India. Solvents such as, dimethylformamide (DMF) and ethanol were purchased from SigmaAldrich (India) and Millipore water received from Milli-Q system (Millipore Inc.) was used throughout the experiments. Dibasic sodium phosphate $\left(\mathrm{Na}_{2} \mathrm{HPO}_{4}\right)$ and mono basic sodium phosphate $\left(\mathrm{NaH}_{2} \mathrm{PO} 4\right)$ were supplied by Sigma-Aldrich (India) and used for preparation of $0.1 \mathrm{M}$ phosphate buffer solution (PBS). Potassium ferro cyanide $\left(\mathrm{K}_{4}\left[\mathrm{Fe}(\mathrm{CN})_{6}\right]\right)$, Potasium ferri cyanide $\left(\mathrm{K}_{3}\left[\mathrm{Fe}(\mathrm{CN})_{6}\right]\right)$ and potassium chloride $(\mathrm{KCl})$ were purchased from SigmaAldrich (India) and used for the electrochemical impedance studies. Dopamine hydrochloride (DA) purchased was also from Sigma-Aldrich (India) and used as an analyte in the electrochemical studies.

In a typical catalyst preparation, copper nitrate and ammonium molybdate at different weight percentages were taken in $50 \mathrm{ml}$ round bottom flask and liquefied with $30 \mathrm{ml}$ of double distilled water and then added $1 \mathrm{~g}$ of $\alpha-\mathrm{Al}_{2} \mathrm{O}_{3}$ nanoparticles to it. There after the components were stirred efficiently for $2 \mathrm{~h}$ at room temperature and dried at $60^{\circ} \mathrm{C}$ overnight, which was then pulverized into fine powder and sintered at $450{ }^{\circ} \mathrm{C}$ for $3 \mathrm{~h}$.

\section{Synthesis process}

The Ni-Cu bi-metal substituted $\alpha$-alumina nanoparticles catalyst in different weight percentages (wt \%) was prepared by a typical wet impregnation method at room temperature. Then the synthesis of c-CNTs was performed on $\mathrm{Ni}-\mathrm{Cu} / \alpha-\mathrm{Al}_{2} \mathrm{O}_{3}$ nanopowder catalyst. The process was carried out by CVD contain a horizontal alumina tube reactor (length $100 \mathrm{~cm}$, inner diameter $60 \mathrm{~mm}$ ) at atmospheric pressure. The catalyst powder in a particular quantity was homogeneously dispersed on a quartz boat, which was subsequently located at the center of the furnace (alumina tube). Afterwards, the powder material was heated to set the reaction temperature under carrier gas of $\mathrm{N}_{2}$ flow as accurately controlled by electronic mass flow meters (Alicat, USA). Later $\mathrm{N}_{2}$ gas flow was closed as it reached the set temperature and source gas of acetylene was flushed out with a choice of flow rates to produce in high yield. In the end, source flow was terminated and $\mathrm{N}_{2}$ flow was continuously sent to CVD reactor to cool down to room temperature. The obtained carbon product yield 
was estimated by the below formula (Somanathan and Pandurangan 2009).

Carbon yield $=\frac{\left(m_{\mathrm{tot}}-m_{\mathrm{cat}}\right)}{m_{\mathrm{cat}}} \times 100$

where $m_{\text {cat }}$ and $m_{\text {tot }}$ are the mass of the catalyst before and after the reaction, respectively. The collected sample was purified by a simple base $(\mathrm{NaOH})$ followed by acid $(\mathrm{HCl})$ treatment to remove alumina support and metal particles from the c-CNTs, respectively (Mohana Krishna et al. 2014).

\section{Physical characterization techniques}

Morphology of the purified sample was examined through a field emission scanning electron microscope (FESEM) SU-6600, Hitachi, Japan, operated at an accelerating voltage of $15 \mathrm{kV}$. The energy dispersive X-ray spectroscopy (EDX), INCA PentaFET-x3 (Oxford Instruments, UK) was performed to identify the elemental composition and purity of the product. High-resolution transmission electron microscope (HRTEM) images were recorded on a TecnaiT20 G2 200 kV, FEI Brand (Netherlands) microscope duly operated at an accelerating voltage of $200 \mathrm{kV}$. A Lab RAM HR (Horiba JOBIN-YVON Raman spectrophotometer) was used to evaluate graphitization of the material. To know the composition distribution along to certain depth of the material, $\mathrm{x}$-ray photoelectron spectroscopy (XPS) was employed with Omicron Nanotechnology, ESCA-14 model (Germany) XPS instrument and obtained peaks were further corrected by adjusting the $\mathrm{C} 1 \mathrm{~s}$ peak to the position of $284.8 \mathrm{eV}$. The magnetic properties of the sample were registered on a vibrating sample magnetometer (VSM 7404 series of LAKESHORE make) with vibrating frequency $8.3 \mathrm{~Hz}$ in the magnetic field range -15 to $+15 \mathrm{kO}_{\mathrm{e}}$ at room temperature.

\section{Results and discussion}

\section{Effect of reaction parameters on the yield}

The reaction parameters powerfully control the yield include catalyst composition, reaction temperature, feedstock gas flow rate and reaction time. Initially, the catalyst activity of $\mathrm{Ni}-\mathrm{Cu}$ loaded $\alpha-\mathrm{Al}_{2} \mathrm{O}_{3}$ was tested against synthesis of c-CNTs. Bi-metal of Ni-Cu wt $\%$ in $1 \mathrm{~g}$ of $\alpha-\mathrm{Al}_{2} \mathrm{O}_{3}$ support was varied to estimate the efficiency of the catalyst, at a constant temperature and acetylene flow rate. It was observed that a minimum yield of carbon deposit found at 5, $5 \mathrm{wt} \%$ of $\mathrm{Ni}-\mathrm{Cu}$ bi-metal with respect to the $\alpha-\mathrm{Al}_{2} \mathrm{O}_{3}$ support. Raise in the both metal wt $\%$ of 10,10 was also obtained a minimum yield of the product, which is due to uneven distribution
Table 1 Carbon yield of $\mathrm{Ni}-\mathrm{Cu} / \alpha-\mathrm{Al}_{2} \mathrm{O}_{3}$ catalyst with different weight percentages

\begin{tabular}{llllc}
\hline $\begin{array}{l}\mathrm{Ni}, \mathrm{Cu} \\
\text { weight }(\%)\end{array}$ & $\begin{array}{l}\text { Temperature } \\
\left({ }^{\circ} \mathrm{C}\right)\end{array}$ & $\begin{array}{l}\text { Reaction } \\
\text { time }(\mathrm{min})\end{array}$ & $\begin{array}{l}\text { Acetylene } \\
\text { flow }(\mathrm{sccm})\end{array}$ & $\begin{array}{l}\text { Carbon } \\
\text { yield } \\
(\%)\end{array}$ \\
\hline 5,5 & 700 & 10 & 50 & 85 \\
10,10 & & & & 55 \\
5,10 & & & 103 \\
10,5 & & & 69 \\
\hline
\end{tabular}

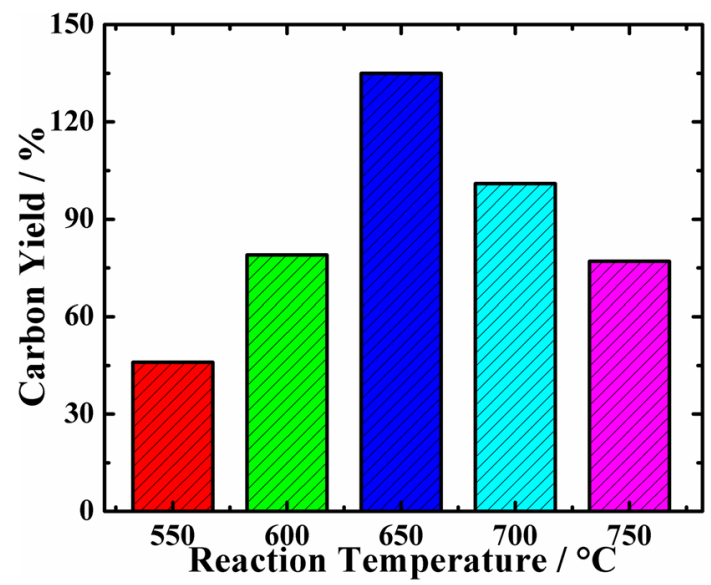

Fig. 1 The catalytic activity of $5,10 \mathrm{wt} \% \mathrm{Ni}-\mathrm{Cu} / \alpha-\mathrm{Al}_{2} \mathrm{O}_{3}$ against temperature for the yield of carbon product

and also result in the formation of bulk, clustered metal particles. Hence, diminishing the number of active sites and surface area of the catalyst thereby affects the growth of c-CNTs. Subsequently altering the $\mathrm{Ni}-\mathrm{Cu}$ content in the support material, a maximum yield of the carbon material is observed at 5, $10 \mathrm{wt} \%$ as described in Table 1. It is anticipated that the optimum loading $(5,10 \mathrm{wt} \% \mathrm{Ni}-\mathrm{Cu})$ provide a better yield than others since double the amount of copper content enhance the growth significantly by activating the nickel surface. This modification of the catalyst is more important as appropriate amounts of $\mathrm{Ni}-\mathrm{Cu}$ in $\alpha-\mathrm{Al}_{2} \mathrm{O}_{3}$ support could play a decisive role in obtaining the high yield.

The effect of temperature was also noted to attain the carbon product in large-scale over the optimized catalyst. The yield was observed using $5,10 \mathrm{wt} \% \mathrm{Ni}-\mathrm{Cu} / \alpha-\mathrm{Al}_{2} \mathrm{O}_{3}$ nanopowder catalyst by changing the temperature between 550 and $750{ }^{\circ} \mathrm{C}$ with $50{ }^{\circ} \mathrm{C}$ interval under the regular growth period of $10 \mathrm{~min}$ along with acetylene flow rate of $50 \mathrm{sccm}$. The minimum yield is found at low temperature (550 and $600{ }^{\circ} \mathrm{C}$ ) reaction. The yield was highly increased (135\%) at a temperature of $650{ }^{\circ} \mathrm{C}$, which depicted in Fig. 1. Temperature higher than $t 650{ }^{\circ} \mathrm{C}$ was also observed a minimum yield of the product. The result of yield at low temperature is attributed to the less catalytic activity of the 5, $10 \mathrm{wt} \%$ 
$\mathrm{Ni}-\mathrm{Cu} / \alpha-\mathrm{Al}_{2} \mathrm{O}_{3}$ catalyst due to sluggish carbon distribution on the metal and also the deficiency of metallic nanoparticles over the support material surface (Balamurugan et al. 2013; Munnik et al. 2015). As a result, the decomposition of the acetylene is reduced at low temperatures. The decrease in carbon deposit at higher than the $650{ }^{\circ} \mathrm{C}$ has ascribed to the metal particles agglomeration leads to deactivation of the catalyst, which is disfavoured for growth. This evidently describes that the maximum yield was attained at $650{ }^{\circ} \mathrm{C}$. Thus, the temperature also plays a significant role to gain the majority yield.

Sequentially to explore the effect of acetylene flow rate, the reaction temperature and the time were maintained at $650{ }^{\circ} \mathrm{C}$ and $10 \mathrm{~min}$, respectively. As the acetylene flow rate increased from 25 to $125 \mathrm{sccm}$, a linear fashion in the decreased amount of carbon deposits is noted from 187 to $67 \%$, respectively, which is also demonstrated in Fig. 2. The decrease in carbon yield with the increase in flow rate is due to the formation of amorphous carbon instead of c-CNTs. And also decrease in carbon yield is probably due to reducing the contact time of the source gas by the catalyst with an increment (Somanathan and Pandurangan 2006). Thus, the variation of flow rate is also helped in achieving the maximum yield of the carbon product.

The reaction time is also considerably influenced in obtaining the high yield by CVD method. A series of experiments were performed under the optimized condition of the temperature of $650{ }^{\circ} \mathrm{C}$ and $25 \mathrm{sccm}$ flow rate and shown in Fig. 3. When the reaction time was varied from 10 to $60 \mathrm{~min}$, the yield also improved from 187 to $266 \%$ up to the reaction time of $30 \mathrm{~min}$, which can also be seen in Fig. 4. Thereafter, no apparent enhancement is noticed up to $60 \mathrm{~min}$ is due to unavailable of catalytic active sites ( $\mathrm{Ni}$ et al. 2006). Hence the time is also considerably influenced on the carbon deposit. Therefore, the maximum yield was carried out

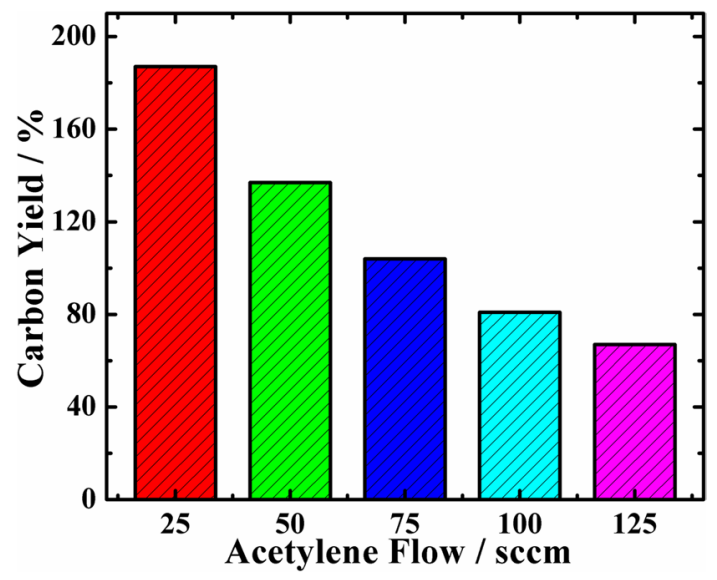

Fig. 2 The yield of carbon product on $5,10 \mathrm{wt} \% \mathrm{Ni}-\mathrm{Cu} / \alpha-\mathrm{Al}_{2} \mathrm{O}_{3}$ as a function of flow rate at a temperature of $650{ }^{\circ} \mathrm{C}$

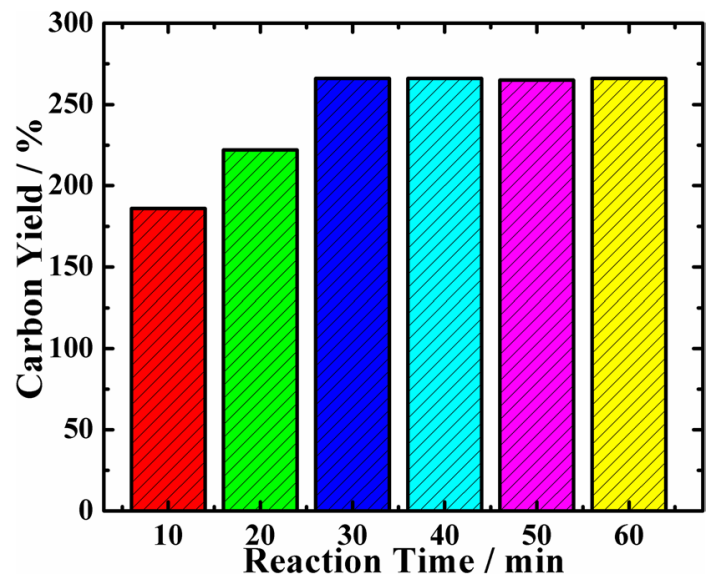

Fig. 3 The $5,10 \mathrm{wt} \% \mathrm{Ni}-\mathrm{Cu} / \alpha-\mathrm{Al}_{2} \mathrm{O}_{3}$ catalytic activity as a function of time at a flow rate of $25 \mathrm{sccm}$ and $650{ }^{\circ} \mathrm{C}$ for the carbon yield

under optimized CVD parameters of 5, $10 \mathrm{wt} \% \mathrm{Ni}-\mathrm{Cu} / \alpha-$ $\mathrm{Al}_{2} \mathrm{O}_{3}$ catalyst, $650{ }^{\circ} \mathrm{C}$ reaction temperature, $25 \mathrm{sccm}$ flow rate and $30 \mathrm{~min}$ of reaction time.

\section{Characterization of c-CNTs}

Figure 5 displays FESEM images of purified sample synthesized over the 5, $10 \mathrm{wt} \% \mathrm{Ni}-\mathrm{Cu}$ substituted $\alpha-\mathrm{Al}_{2} \mathrm{O}_{3}$ nanopowder at $650{ }^{\circ} \mathrm{C}$. From the FESEM observation, typically stretched coil morphology of the material is observed and confirms the formation of c-CNTs. And the material appeared as dense bundles that may also be evident for high yield. We have estimated that the approximate length might be several micrometers. Measurement of exact length is difficult as of their twisting nature. A Careful examination of the FESEM micrographs indicating the coil diameter is in the range of $80-100 \mathrm{~nm}$ and shows a

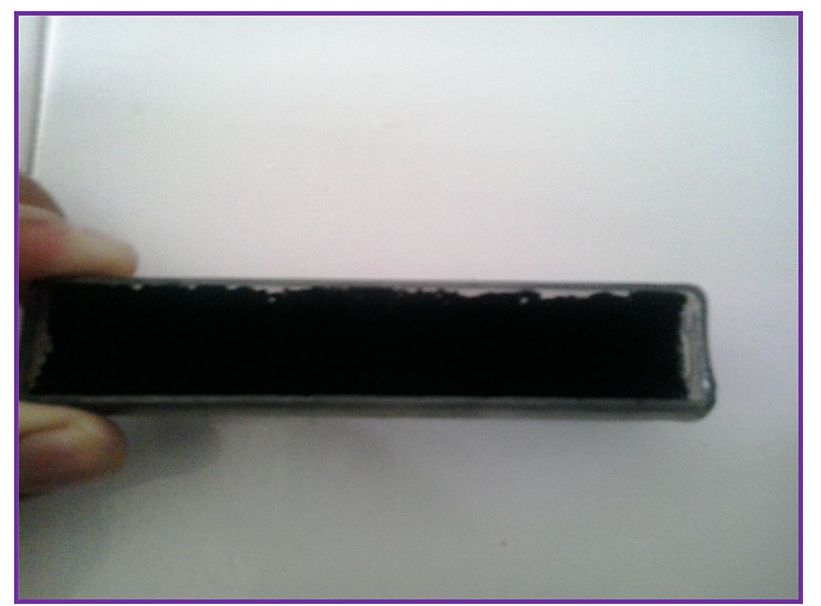

Fig. 4 Optical image of as-grown c-CNTs 


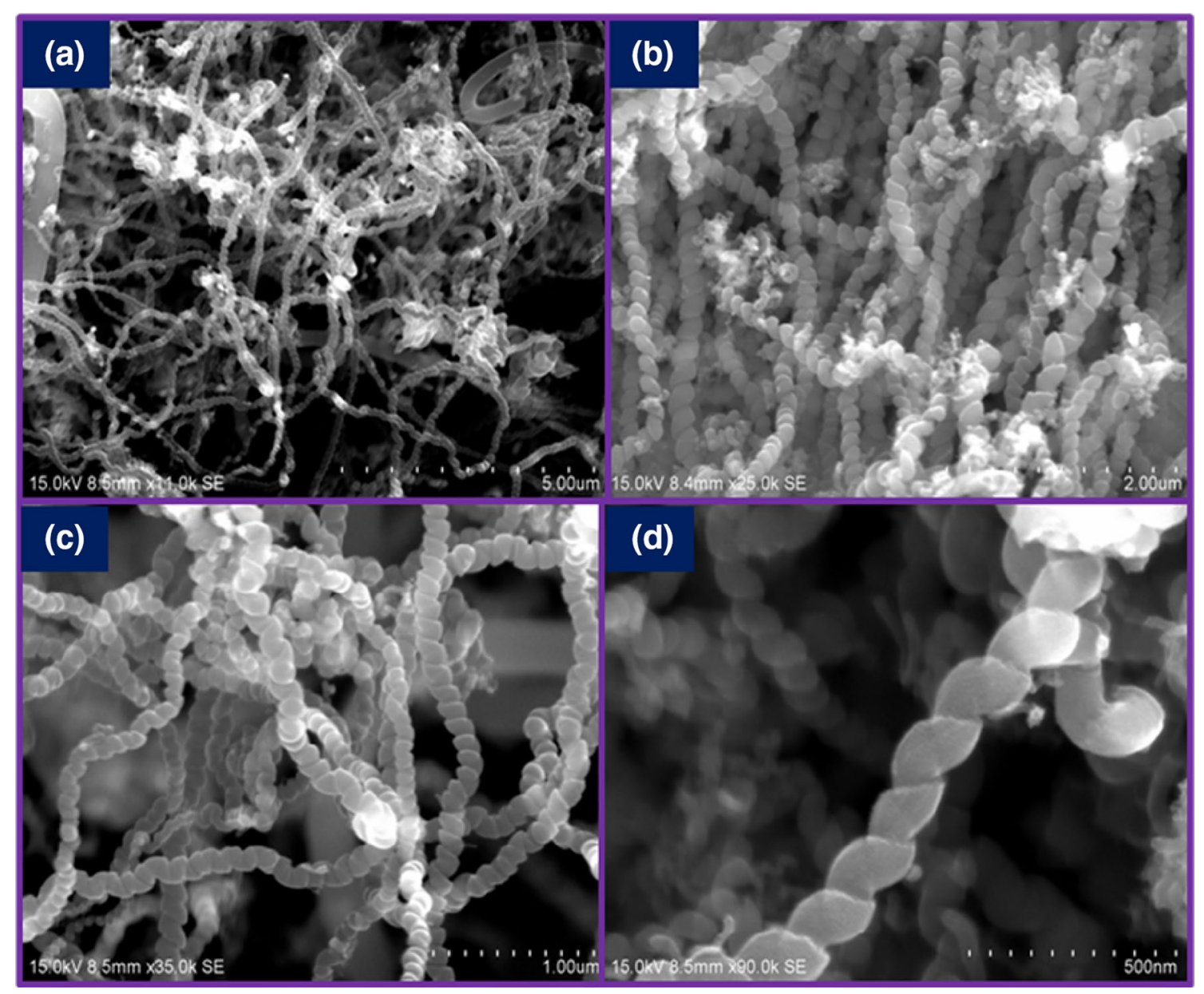

Fig. 5 FESEM images of c-CNTs produced at $650{ }^{\circ} \mathrm{C}$ at different magnifications

uniform coiled structure of the material. Also, there are no noticeable adhered catalyst particles on the surface, which indicate the c-CNTs material consist of a smooth and clean surface. This is also evident from HRTEM examination results shown in Fig. 8, and in which catalyst free and smooth outer walls of c-CNTs are observed and also performed EDX analysis.

Energy dispersive X-ray spectroscopy (EDX) analysis is applied to evaluate the purity of the product by estimating the composition of elements and their atomic percentages in the material. Figure 6 shows, EDX spectrum of the purified c-CNTs. The considerably reduced atomic proportion of $\mathrm{Al}, \mathrm{O}, \mathrm{Ni}$ and $\mathrm{Cu}$ in the final sample is observed compared to that of the $5,10 \mathrm{wt} \% \mathrm{Ni}-\mathrm{Cu} / \alpha-\mathrm{Al}_{2} \mathrm{O}_{3}$ catalyst. The high-intensity of $\mathrm{C}$ peak in EDX spectrum indicates the high purity of the material and other impurities in the sample are removed almost by the subsequent purification process. The other peak for gold $(\mathrm{Au})$ is also observed in the spectrum comes from the Au sputtering while EDX sample preparation. Hence, the purification procedure was removed most of the contamination from the material at room temperature.

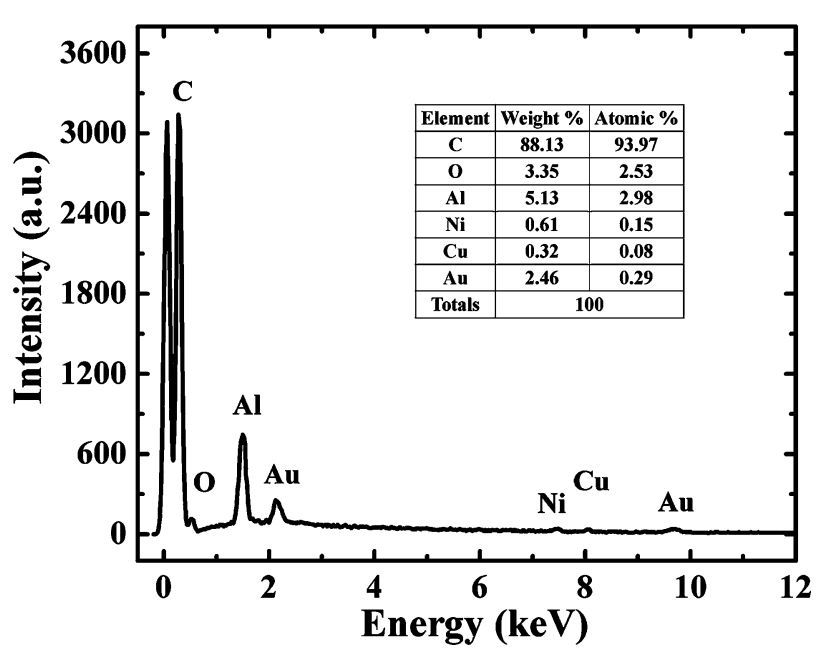

Fig. 6 EDX spectrum of c-CNTs with atomic percentages 


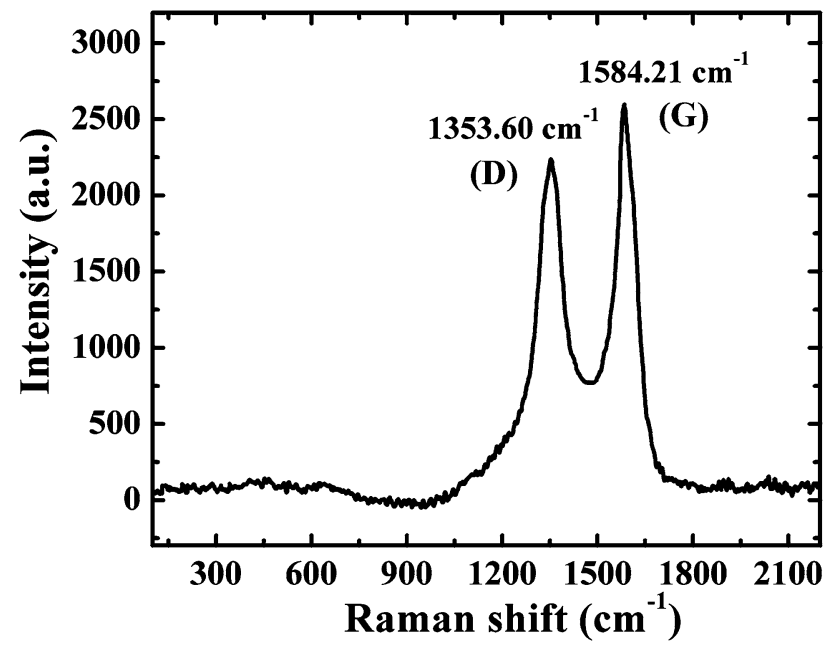

Fig. 7 Raman spectrum of purified c-CNTs
Raman spectroscopy can frequently characterize the crystalline nature, purity and defects in the different types of carbonaceous materials. Figure 7 represents the Raman spectrum of c-CNTs, in that a high peak at $1584.21 \mathrm{~cm}^{-1}$ and another peak at $1353.60 \mathrm{~cm}^{-1}$ are observed and ascribed to the Raman G (graphitized band) and D (disordered band) band, respectively (Manikandan et al. 2015). More specifically, the G-band is a feature of $\mathrm{E}_{2 \mathrm{~g}}$ mode associated with the vibration of $\mathrm{sp}^{2}$ bonded crystalline carbon, whereas the D-band corresponds to $\mathrm{A}_{1 \mathrm{~g}}$ mode correlate to the disorder features due to amorphous carbon and defects in the side walls. The existence of high-intensity D band also in the Raman spectrum is due to twisting morphology or coil structure of the nanotubes, disordered graphitic layers and as well as impurities in the material. The intensity ratio between $\mathrm{G}$ band and $\mathrm{D}$ band $\left(I_{\mathrm{G}} / I_{\mathrm{D}}\right)$ is found to be 1.16 , indicating well graphitization and a certain degree of crystallinity in the product. Thus, the synthesized c-CNTs are well graphitized and crystalline material.

HRTEM observation reveals that the high yield carbon product from the $5,10 \mathrm{wt} \% \mathrm{Ni}-\mathrm{Cu} / \alpha-\mathrm{Al}_{2} \mathrm{O}_{3}$ catalyst have
Fig. 8 HRTEM images of c-CNTs grown on $5,10 \mathrm{wt} \%$ $\mathrm{Ni}-\mathrm{Cu} / \alpha-\mathrm{Al}_{2} \mathrm{O}_{3}$ catalyst

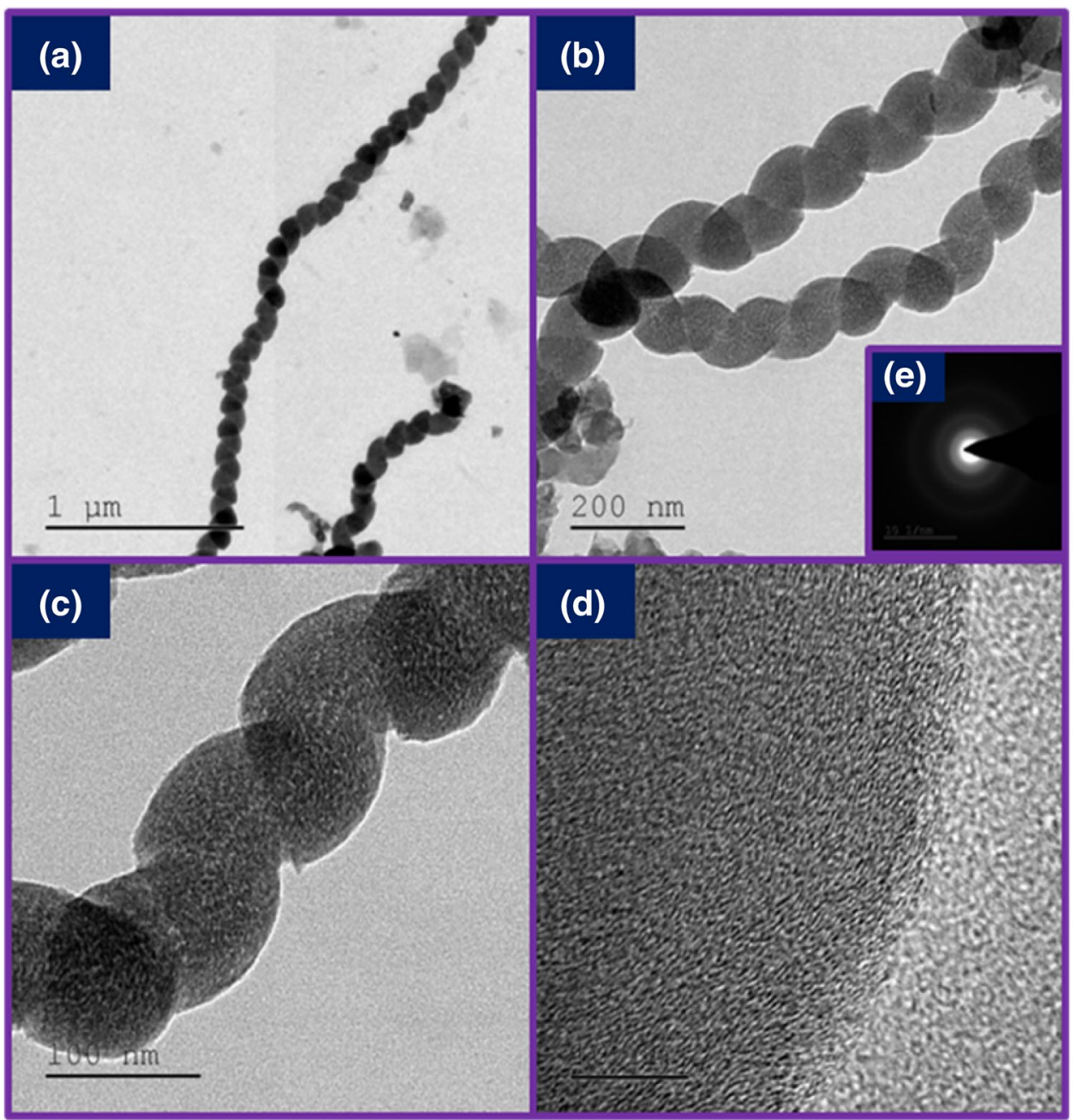


CNTs with twisted morphology. It proves that coil shape of CNTs and a small hollow core structure is not visible in the tubes due to many concentric walls around the central axis are more and also can be seen in FESEM images. The average diameter is calculated to be approximately $90 \mathrm{~nm}$ for individual tubes and all are in uniform dia. From Fig. 8, it is also evident that the obtained product is well graphitized, crystalline and high purity. The selected area electron diffraction (SAED) pattern was depicted in Fig. 8e describes the diffraction rings which correspond to graphite (002), (100), and (110) layer planes, respectively. In general, it is believed that coiled carbon formation involves the conversion of a transition metal catalyst to promote non-uniform extrusion of carbon from the active catalyst surface (Hanus and Harris 2010). Thus the $5,10 \mathrm{wt} \% \mathrm{Ni}-\mathrm{Cu} / \alpha-\mathrm{Al}_{2} \mathrm{O}_{3}$ catalyst show a vital role in determining the growth and high yield is under the optimized condition.

To understand the chemical composition, purity of the material and to support the EDX analysis, we have performed XPS investigation on the surface of purified c-CNTs. Figure 9 shows the survey scan and high-resolution XPS spectra of individual elements in the final material. Obtained spectra consist of one major peak and two minor peaks are presented at the binding energy of 284.6 and $74.6,532.0 \mathrm{eV}$ corresponding to the core level of $\mathrm{C} 1 \mathrm{~s}$ and $\mathrm{Al} 2 \mathrm{p}, \mathrm{O} 1 \mathrm{~s}$, respectively. It denotes that the intensity of $\mathrm{sp}^{2}$ carbon binding energy is very high compared to that of $\mathrm{O}$ and $\mathrm{Al}$ peak intensities, due to the removal of impurities from the product. This result is in good agreement with the data obtained with EDX investigation and supporting the formation of the high-quality product. High-resolution spectra in Fig. 9e, $\mathrm{f}$
Fig. 9 XPS spectra of c-CNTs (survey and high-resolution spectra)
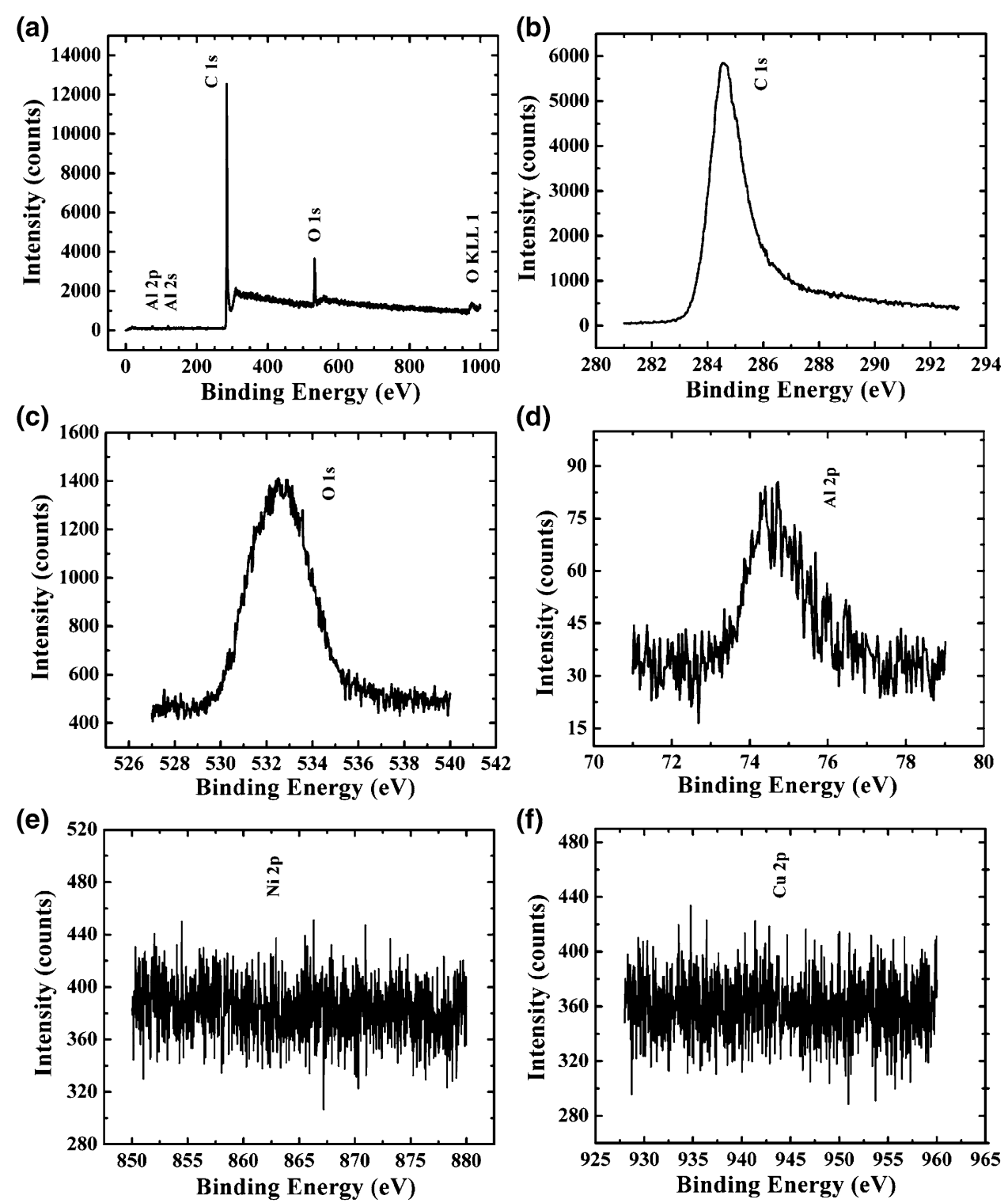

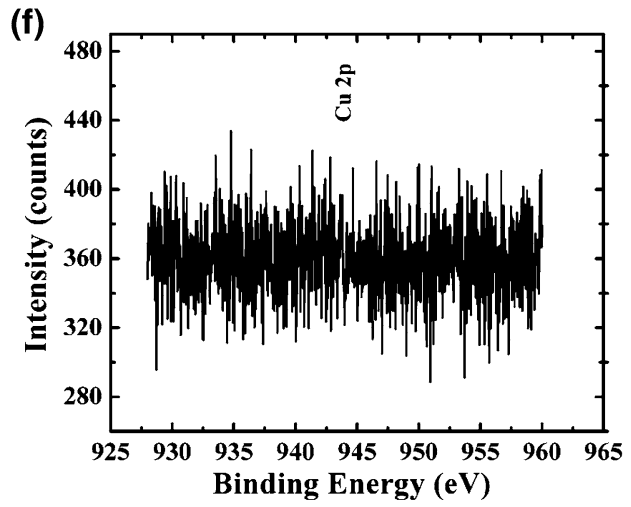


also describes the absence of peaks at $922,458 \mathrm{eV}$ for core level of $\mathrm{Ni} 2 \mathrm{p}$ and $\mathrm{Cu} 2 \mathrm{p}$ are indicating lack of such catalytic particles on the surface of c-CNTs. Hence the purification process has made the product without impurities ultimately leading to obtaining excellent material.

\section{Magnetic properties of c-CNTs}

Magnetism of carbon-based materials is a challenging area for both fundamental research and possible applications. A special consideration are CNTs filled with ferromagnetic metals ( $\mathrm{Fe}, \mathrm{Co}, \mathrm{Ni})$. Carbon shell protects metallic nanowires from oxidation and safely separates them from each other. Nanotubes with different structural parameters, such as diameter, wall width and packaging of graphene layers differ much in physical properties. Magnetic properties of metal-filled CNTs are dependent on tubes characteristics, as well as the distribution of metal, the ratio between the tube and inner metallic nanowire diameters, and the filling rate. The magnetic properties of the purified product were estimated by VSM analysis at room temperature (RT) and followed the present work ( $\mathrm{Lu} \mathrm{1995).} \mathrm{It} \mathrm{is} \mathrm{very} \mathrm{much}$ interesting to explore their magnetic properties due to their unique 3D coil structure and potential biomedical electronic applications such as MRI, cell labelling, cell tracking and also spintronic devices. The plot of magnetic moment versus magnetic field in the range from -15 to $+15 \mathrm{kO}_{\mathrm{e}}$ of the sample at room temperature is shown in Fig. 10. The data reveals that the measured magnetization curve has hysteresis loop and it provides the relation between the magnetization $(M)$ and the applied field $(H)$. The narrow hysteresis loop is in Fig. 10 indicating the soft ferromagnetism nature of the synthesized material at room temperature. This result has similarity with other researcher reports presented on c-CNTs with magnetic properties (Tang et al. 2010). The plot also

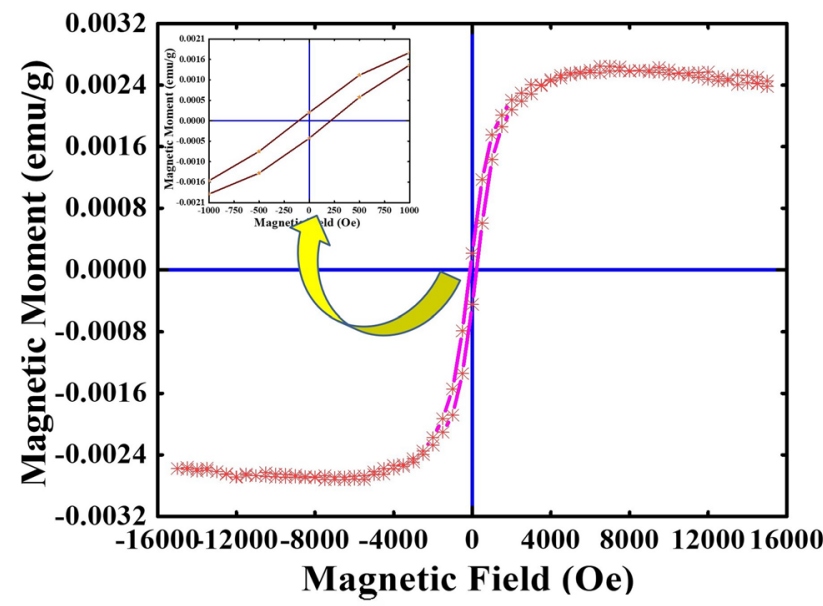

Fig. 10 VSM plot of c-CNTs at room temperature shows the relatively low filed saturation magnetization in the product. The relatively low values of the observed coercivity $\left(H_{\mathrm{c}}\right) 159 \mathrm{O}_{\mathrm{e}}$, retentivity $\left(M_{\mathrm{r}}\right) 0.0043 \mathrm{emu} / \mathrm{g}$ and saturation magnetization $\left(M_{\mathrm{s}}\right) 0.0027 \mathrm{emu} / \mathrm{g}$ are exposed the soft ferromagnetism nature of c-CNTs at room temperature. This significant magnetic property is due to the induced magnetism, which is caused by defective sites such as vacancies, impurities or structural defects by its distinctive coil structure. This might lead to soft ferromagnetism when the defects are sufficiently dense (Cespedes et al. 2004; Friedman et al. 2010). Thus, the purified material show a low level of soft ferromagnetism at room temperature which is also beneficial with the combination of hybrid materials for transformers and motor cores in with AC electrical applications (Garcia-Merino et al. 2017; Raghasudha et al. 2013).

\section{Conclusion}

We have successfully demonstrated the large-scale synthesis (high yield) of c-CNTs over the bi-metal impregnated $\alpha$-alumina nanoparticles support material by CVD method. The purified material was characterized with FESEM, EDX, HRTEM, XPS, and Raman spectroscopy techniques. The resultant product has highly spring-like (coil) carbon nanostructures in extensive lengths with excellent purity. Well graphitized and high yield of carbon product was achieved under optimized CVD parameters. The result also supports the activity of the bi-metal impregnated $\alpha$-alumina nanoparticles catalyst in the determination of the high yield, well graphitization and structure of the material. Moreover, they show soft ferromagnetism at room temperature which is beneficial in AC electrical applications.

Acknowledgements One of the authors T. Somanathan would like to thank Department of Science and Technology (DST) India for providing project (SR/FT/CS-111/2011) under Fast Track Young Scientist Scheme and also thank Vels University for providing infrastructure facilities.

\section{References}

Akagi K, Tamura R, Tsukada M (1995) Electronic structure of helically coiled cage of graphitic carbon. Phys Rev Lett 74:2307-2310

Amelinck A, Zhang XB, Bernaerts D, Zhang XF et al (1994) A formation mechanism for catalytically grown helix-shaped graphite nanotubes. Science 265:635-639

Balamurugan J, Pandurangan A, Thangamuthu R, Senthilkumar SM (2013) Effective synthesis of well-graphitized carbon nanotubes on bimetallic sba-15 template for use as counter electrode in dyesensitized solar cells. Ind Eng Chem Res 52:384-393

Cespedes O, Ferreira MS, Sanvito S, Kociak M, Coey JMD (2004) Contact induced magnetism in carbon nanotubes. J Phys Condens Matter 16:L155 
Chen X, Zhang S, Dikin DA, Ding W, Ruoff RS, Pan L, Nakayama Y (2003) Mechanics of a carbon nanocoil. Nano Lett 3:1299-1304

Cherusseri J, Sharma R, Kar KK (2016) Helically coiled carbon nanotube electrodes for flexible supercapacitors. Carbon 105:113-125

Choi C, Kim SH, Sim HJ et al (2015) Stretchable, weavable coiled carbon nanotube/ $\mathrm{MnO}_{2}$ /polymer fiber solid-state supercapacitors. Sci Rep 5:1-6

Friedman AL, Chun H, Jung YJ et al (2010) Possible room-temperature ferromagnetism in hydrogenated carbon nanotubes. Phys Rev B 81:115461-115464

Garcia-Merino JA et al (2017) Magneto-conductive encryption assisted by third-order nonlinear optical effects in carbon/metal nanohybrids. Mater Res Express 4:035601

Hanus MJ, Harris AT (2010) Synthesis, characterisation and applications of coiled carbon nanotubes. J Nanosci Nanotechnol 10:2261-2283

Iijima S (1991) Helical microtubules of graphitic carbon. Nature 354:56-58

Kennedy J, Fang F, Manikandan E et al (2017) Synthesis and enhanced field emission of zinc oxide incorporated carbon nanotubes. Diamond Relat Mater 71:79-84

Khani N, Yildiz M, Koc B (2016) Elastic properties of coiled carbon nanotube reinforced nanocomposite: a finite element study. Mater Des 109:123-132

Lau KT, Lu M, Hui D (2006) Coiled carbon nanotubes: synthesis and their potential applications in advanced composite structures. Compos B 37:437-448

Lee SH, Park J, Kim HR et al (2016) Synthesis of carbon nanotube fibers using the direct spinning process based on design of experiment (DOE). Carbon 100:647-655

Li M, Li N, Shao W, Zhou C (2016) Synthesis of carbon nanofibers by CVD as a catalyst support material using atomically ordered $\mathrm{Ni}_{3} \mathrm{C}$ nanoparticles. Nanotechnology 27:505706-505714

Liu L, Liu F, Zhao J (2014) Curved carbon nanotubes: from unique geometries to novel properties and peculiar applications. Nano Res 7:626-657

Lu JP (1995) Novel magnetic properties of carbon nanotubes. Phys Rev Lett 74:1123-1126

Ma D, Ding H, Wang X, Yang N, Zhang X (2017) The unexpected thermal conductivity from graphene disk, carbon nanocone to carbon nanotube. In J Heat Mass Transfer 108:940-944

Manikandan E, Kennedy J, Kavitha G et al (2015) Hybrid nanostructured thin-films by PLD for enhanced field emission performance for radiation micro-nano dosimetry applications. J Alloys Compd 647:141-145

Matsui K, Segawa Y, Namikawa T, Kamada K, Itami K (2013) Synthesis and properties of all-benzene carbon nanocages: a junction unit of branched carbon nanotubes. Chem Sci 4:84-88

Mohana Krishna V, Somanathan T (2016) Efficient strategy to $\mathrm{Cu} / \mathrm{Si}$ catalyst into vertically aligned carbon nanotubes with bamboo shape by CVD technique. Bull Mater Sci 39:1079-1084

Mohana Krishna V, Abilarasu A, Somanathan T, Gokulakrishnan N (2014) Effective synthesis of well graphitized high yield bamboolike multi-walled carbon nanotubes on copper loaded $\alpha$-alumina nanoparticles. Diamond Relat Mater 50:20-25
Motaung DE, Moodley MK, Manikandan E, Coville NJ (2010) In situ optical emission study on the role of $\mathrm{C}_{2}$ in the synthesis of singlewalled carbon nanotubes. J Appl Phy 107:044308-044323

Motojima S, Hasegawa I, Kagiya S et al (1993) Preparation of coiled carbon fibers by pyrolysis of acetylene using a Ni catalyst and sulfur or phosphorus compound impurity. Appl Phys Lett 62:2322-2323

Munnik P, De Jongh PE, De Jong KP (2015) Recent developments in the synthesis of supported catalysts. Chem Rev 115:6687-6718

Ni L, Kuroda K, Nakamura J (2006) Kinetic study of carbon nanotube synthesis over $\mathrm{Mo} / \mathrm{Co} / \mathrm{MgO}$ catalysts. Carbon 44:2265-2272

Park SH, Yun DJ, Theilmann P, Bandaru PR (2013) Superior electrical and mechanical characteristics observed through the incorporation of coiled carbon nanotubes in comparison to non-coiled forms in polymers. Polymer 54:1318-1322

Raghasudha M, Ravinder D, Veerasomaiah P (2013) Magnetic properties of Cr-substituted Co-ferrite nanoparticles synthesized by citrate-gel autocombustion method. J Nan Chem 3:1-6

Raghubanshi H, Dikio ED, Naidoo EB (2016) The properties and applications of helical carbon fibers and related materials: a review. J Ind Eng Chem 44:23-42

Sai Krishna K, Eswaramoorthy M (2007) Novel synthesis of carbon nanorings and their characterization. Chem Phys Lett 433:327-330

Segawa Y, Yagi A, Matsui K, Itami K (2016) Design and synthesis of carbon nanotube segments. Angew Chem 55:5136-5158

Somanathan T, Pandurangan A (2006) Effective synthesis of singlewalled carbon nanotubes using $\mathrm{Ni}-\mathrm{MCM}-41$ catalytic template through chemical vapor deposition method. Ind Eng Chem Res 45:8926-8931

Somanathan T, Pandurangan A (2009) Direct synthesis of vanadium substituted mesoporous MCM-41 molecular sieves: a systematic study for the growth of SWNTs. J Porous Mater 16:657-665

Tang N et al (2010) Helical carbon nanotubes: catalytic particle sizedependent growth and magnetic properties. ACS Nano 4:241-250

Volodin A, Buntinx D, Ahlskog M, Fonseca A, Nagy JB, Haesendonck CV (2004) Coiled carbon nanotubes as self-sensing mechanical resonators. Nano Lett 4:1775-1779

Wang P, Xiao P, Zhong S, Chen J, Lin H, Wu XL (2016) Bamboo-like carbon nanotubes derived from colloidal polymer nanoplates for efficient removal of bisphenol A. J Mater Chem A 4:15450-15456

Zaeria MM, Rad SZ (2015) Elastic behaviour of carbon nanocoils: a molecular dynamics study. AIP Adv 5:117114-117120

Zhao J, Zhang J, Su Y et al (2012) Synthesis of straight multi-walled carbon nanotubes by arc discharge in air and their field emission properties. J Mater Sci 47:6535-6541

Publisher's Note Springer Nature remains neutral with regard to jurisdictional claims in published maps and institutional affiliations. 